\title{
Pneumonia pós-obstrutiva: um caso insólito
}

\author{
Postobstructive pneumonia: an unusual presentation
}

Doente do sexo masculino, de 50 anos de idade, com défice cognitivo por atraso do desenvolvimento psicomotor na infância. Observado por queixas de tosse persistente e expetoração mucopurulenta desde há mais de um ano e meio, sem melhoria sintomatológica após vários cursos de antibioterapia empírica. Apresentava diminuição auscultatória do murmúrio vesicular e da transmissão das vibrações vocais na metade inferior do hemitórax direito. Analiticamente com insuficiência respiratória hipoxémica e síndrome inflamatória sistémica. Efetuada radiografia de tórax, com evidência de hipotransparência a nível do terço inferior do campo pulmonar direito, e hiperdensidade arredondada para-hilar ipsilateral (Figura 1). Realizada tomografia computadorizada a confirmar imagem ovoide de densidade metálica no brônquio lobar inferior direito, e consolidação pulmonar a jusante, compatível com processo infecioso obstrutivo. Iniciada antibioterapia empírica com amoxicilina/ácido clavulânico e clindamicina, e medicado com corticoide em alta dose. Efetuada vídeobroncofibroscopia rígida, com evidência de secreções purulentas abundantes na árvore brônquica direita a obstruir totalmente 0 brônquio principal; após aspiração, observado corpo estranho (moeda de 1 cêntimo) a nível do tronco intermédio - o qual foi retirado com pinça (Figura 2). Efetuada biopsia brônquica, com exame histológico a confirmar tecido de granulação parcialmente revestido por epitélio pavimentoso estratificado e do tipo respiratório, sem displasia ou sinais de malignidade.

0 diagnóstico de pneumonia pós-obstrutiva (PPO) deve ser equacionado nos casos de infeção respiratória com fraca resposta ao tratamento convencional. Apesar de ser mais comum em crianças, a aspiração de corpos estranhos também ocorre na idade adulta ${ }^{1}$. A persistência de um corpo estranho endobrônquico compromete os mecanismos locais de defesa, podendo condicionar fenómenos de atelectasia ou a formação de cavernas². Os microrganismos mais frequentemente implicados incluem estreptococos, Staphylococcus aureus e Pseudomonas aeruginosa, bem como bacilos Gram-negativos e anaeróbios da flora orofaríngea ${ }^{3,4}$. A antibioterapia empírica deve ter em conta o contexto epidemiológico, amoxicilina/ácido clavulânico deve ser considerada como a primeira opção e alternativas incluem piperacilina/tazobactam, carbapenemes, cefepime, ou a associação de clindamicina com ciprofloxacina ou com amoxicilina/ ácido clavulânico.

0 controlo do foco infecioso e a administração de antibióticos de largo espectro conduzem normalmente à resolução da PPO, preconizando-se um prolongamento da antibioterapia até 4 a 8 semanas, dependendo da resposta clínica ${ }^{3,4}$. A corticoterapia pode contribuir para a resolução do processo inflamatório secundário à obstrução ${ }^{4}$.
Figura 1. Radiografia de tórax; hipotransparência a nível do terço inferior do campo pulmonar direito e hiperdensidade arredondada para-hilar ipsilateral

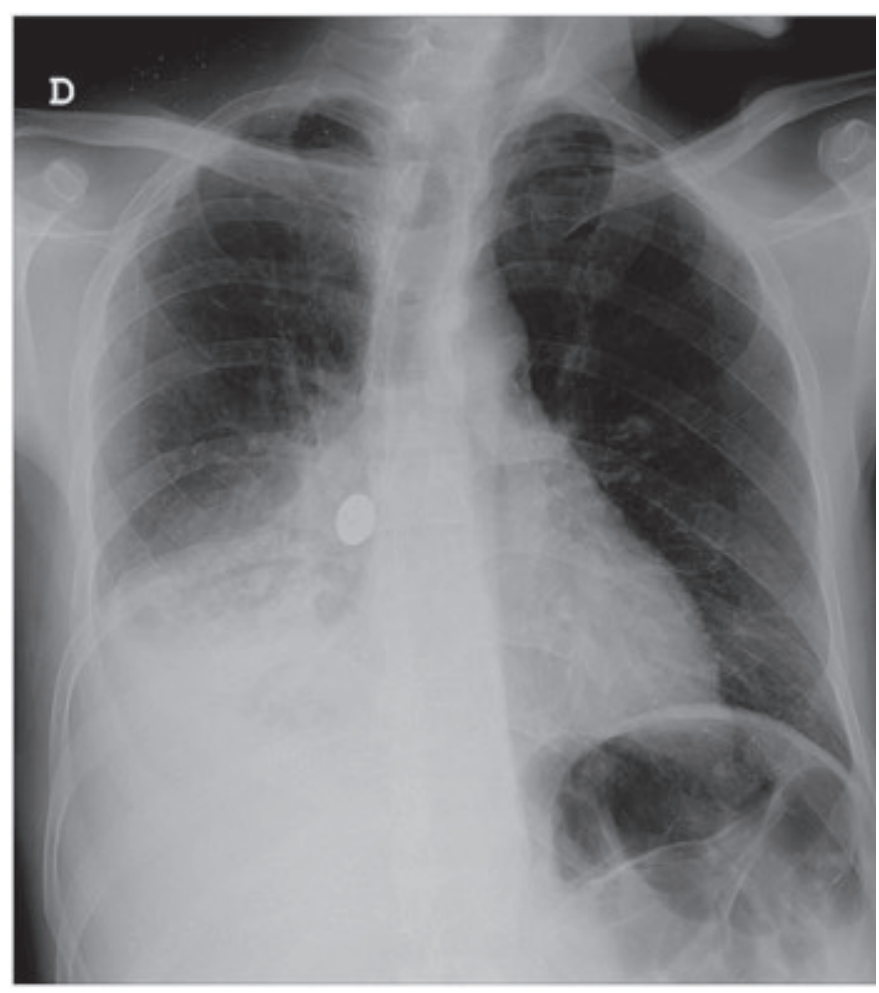

Figura 2. Broncofibroscopia rígida: secreções purulentas abundantes na árvore brônquica direita a obstruir totalmente 0 brônquio principal; após aspiração, observado corpo estranho (moeda de 1 cêntimo) a nível do tronco intermédio
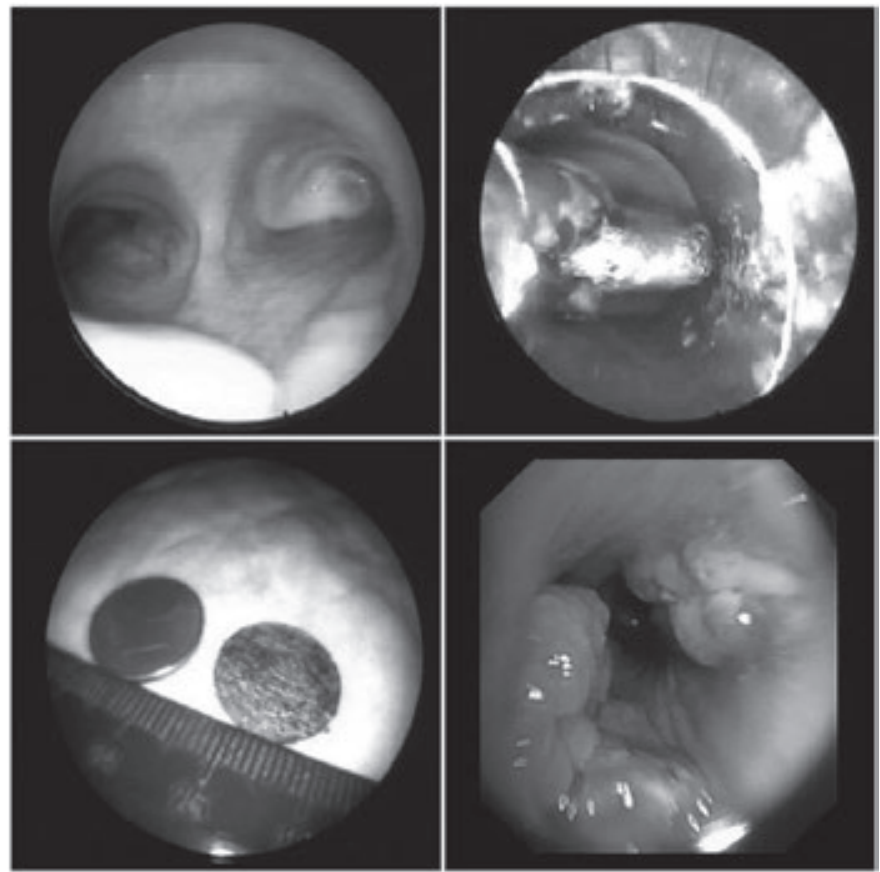


\section{Bibliografia}

1. Baharloo F, Veyckemans F, Francis C, Biettlot MP, Rodenstein DO. Tracheobronchial foreign bodies: presentation and management in children and adults. Chest. 1999 May;115(5):1357-62.

2. Prather $A D$, Smith TR, Poletto DM, Tavora F, Chung JH, Nallamshetty L, Hazelton TR, Rojas CA. Aspiration-Related Lung Diseases. J Thorac Imaging. 2014 Sep;29(5):304-9.

3. Lim WS, Baudouin SV, George RC, Hill AT, Jamieson C, Le Jeune I, Macfarlane JT, Read RC, Roberts HJ, Levy ML, Wani M, Woodhead MA; Pneumonia Guidelines Committee of the BTS Standards of Care Committee. BTS guidelines for the management of community acquired pneumonia in adults: update 2009. Thorax. 2009 0ct;64 Suppl 3:iii1-55.

4. Mandell LA, Wunderink RG, Anzueto A, Bartlett JG, Campbell GD, Dean NC, Dowell SF, File TM Jr, Musher DM, Niederman MS, Torres A, Whitney CG; Infectious Diseases Society of America; American Thoracic Society. Infectious Diseases Society of America/American Thoracic Society consensus guidelines on the management of community-acquired pneumonia in adults. Clin Infect Dis. 2007 Mar 1;44 Suppl 2:S27-72.

\section{Diagnóstico:}

Pneumonia pós-obstrutiva: um caso insólito de aspiração de corpo estranho

\section{João Caiano Gil, Eduardo Eiras}

Serviço de Medicina Interna. Hospital Pedro Hispano. Unidade Local de Saúde de Matosinhos, EPE. Senhora da Hora. Portugal.

Correspondencia: joao.gil@ulsm.min-saude.pt

Como citar este artículo: Caiano Gil J, Eiras E.

Pneumonia pós-obstrutiva: um caso insólito de aspiração de corpo estranho Galicia Clin 2015: 76 (1):37-38 Recibido: 23/7/2014; Aceptado: 19/12/2014

\section{Normas de publicación Galicia Clínica}

Galicia Clínica es la revista oficial de la Sociedad Gallega de Medicina Interna (SOGAMI). Se publican 4 números al año, simultáneamente en papel y en www.galiciaclinica.info, incluyéndose en el segundo de ellos las comunicaciones enviadas a la correspondiente Reunión Ordinaria de la SOGAMI.

GALCIA CLIINICA evaluará para su publicación trabajos médicos relacionados preferentemente con la Medicin Interna y sus subespecialidades, y/o con problemas médicos prevalentes en la Comunidad Autónoma de Galicia. Se admitirán para evaluación trabajos en castellano, gallego, inglés y portugués.

Para el envío de originales se ha habilitado un formulario en la pagina web www.galiciaclinica.info. El sisten confirmará la entrega y permitirá consultar el estado del manuscrito. No se aceptarán originales enviados por otros métodos.

El comité editorial, eventualmente con la ayuda de revisores externos, evaluará los trabajos enviados decidiendo si procede su publicación si es necorio relizar correcciones o si se desestima la publicación Una vez aceptado,

Los trabajos reunirán los requisitos de uniformidad habituales en revistas biomédicas. Dichos requisitos se pueden consultar en "Uniform Requirements for Manuscripts Submitted to Biomedical Journals: Writing and Editing for Biomedical Publication, Updated April 2010", disponible en http://www.icmje.org. Se recomienda encarecidament leer en especial la sección "Preparing a Manuscript for Submission to a Biomedical Journal" (http://www.icmje.org manuscript__ prepare.html) y seguir fielmente sus indicaciones a la hora de redactar el trabajo a enviar.

Se recomienda el empleo de los programas más habituales de edición de texto (E.., Word) tanto para el texto como para las tablas.

Dado que la mayoría de las páginas se imprimen en blanco y negro, se aconseja evitar en tablas y figuras en la medida de lo posible el uso de colores o tramas que no tengan el adecuado contraste para su identificación.

Las figuras o imágenes se enviarán en archivo aparte, como archivo de imagen (jpeg o similar) o como PDF con una resolución de 300 ppp. a tamaño de impresión definitivo.

La revista presenta las siguientes secciones:

Editoriales

Habitualmente encargados por la dirección de la revista. Su extensión máxima será de 8 páginas de 30 líneas y se admitirá una figura 0 una tabla y quince citas bibliográficas.

El número máximo de firmantes será de dos.

Originales

Trabajos de investigación sobre cualquier aspecto médico. La estructura general de los trabajos será la tradicional: Título: en el idioma original y en inglés, Resumen y Abstract en inglés, Palabras clave y Key words (que deben corresponder a los medical subjets headings -MESH- del Index Medicus), Introducción, Material y métodos, Re sultados, Discusión, Bibliografía

La extensión máxima recomendada del texto es de 20 páginas de 30 líneas, a las que se podrán añadir 5 figuras y 5 tablas, y un máximo de 30 citas bibliográficas.

El número máximo de firmantes será de ocho.

Originales breves

Trabajos de investigación que por sus características no precisan un mayor espacio. Estructura similar a la de los originales. Su extensión máxima será de 10 páginas de 30 lineas, 3 figuras, 3 tablas y 20 citas bibliográficas. El número máximo de firmantes será de seis.
Habitualmente encargadas por la dirección de la revista. La extensión máxima recomendada del texto es de 30 páginas de 30 lineas, a las que se podrán añadir 6 figuras y 6 tablas, y un máximo de 50 citas bibliográficas. El número máximo de firmantes será de tres.

Preguntas clínicas

En esta sección se tratará de responder de forma concreta y sucinta a preguntas clínicas concretas que, bien han motivado una controversia, o cuestionan actitudes arraigadas en la práctica diaria. La extensión máxima será de 6 páginas de 30 líneas, dos figuras y dos tablas y 15 citas bibliográficas.

El número máximo de firmantes será de dos.

Notas clínicas

Descripción de casos clinicos de excepcional interés. Constarán de una breve introducción, caso clínico, y discusión correspondiente. Su extensión máxima será de 6 páginas, 2 figuras y dos tablas y 15 citas bibliográficas. El número máximo de firmantes será de cuatro.

Cartas al director

Comentarios, opiniones u observaciones sobre los diversos trabajos publicados con anterioridad en la revista. La extensión máxima será de 4 páginas de 30 líneas y se admitirá una figura o una tabla y diez citas bibliográficas. El número máximo de firmantes será de dos.

Imágenes médicas

Imágenes curiosas, insólitas o demostrativas. Se acompañarán con un texto breve, como máximo 1 página de 30 líneas, en el que se explique el caso clínico, con una breve discusión acerca de la importancia de la imagen.

El número máximo de firmantes será de dos.

Resúmenes de Tesis doctorales

Elaborados por el autor, describirán el trabajo realizado; su extensión máxima será de 2 páginas de 30 líneas. Debe incluirse un apéndice con los datos correspondientes a Universidad, departamento, director de la tesis y fecha de presentación.

Otros

La dirección de la revista considerará para su publicación cualquier artículo relacionado con la medicina en cualquier aspecto, aunque no se incluya exactamente dentro de los supuestos anteriores. En este caso se recomienda antes de su envio contactar con la dirección para acordar las características del mismo.

En el caso de que los trabajos enviados incluyan imágenes, figuras, tablas o textos sometidos a copyright, será responsabilidad de los autores la obtención de los permisos necesarios para su publicación.

Todas las opiniones o afirmaciones expresadas en los artículos corresponden a los autores de los mismos. Tanto e comité editorial como la SOGAMI declinan cualquier responsabilidad a este respecto.

Los trabajos publicados serán propiedad de GALICIA CLÍNICA, cediendo los autores todos los derechos a la misma. 